\title{
Scavenging Characteristics of a Two-Stroke-Cycle Engine as Determined by Skip-Cycle Operation
}

\author{
P. M. Ku and T. F. Trimble
}

\begin{abstract}
A method for determining the mass fraction of fresh charge in the cylinder of the twostroke-cycle engine, from measurements of engine power under normal operation and with engine fired only once in several cycles of operation is described. The results obtained from a crankcase-scavenged engine are presented.
\end{abstract}

\section{Introduction}

The two-stroke cycle engine, in order to develop one power cycle for every revolution of the crankshaft, must rely on the action of an auxiliary device, known as the scavenging pump, to expel the combustion products from the cylinder and to fill the cylinder with fresh charge. The scavenging pump may be and frequently is physically separate from the engine cylinder proper. In the crankcase-scavenged engine, the cylinder-crankcase-piston combination serves as the scavenging pump.

The ideal objective of the scavenging process is, of course, to replace completely the combustion products in the engine cylinder with fresh charge delivered through the inlet ports, without meantime losing any of the fresh charge through the exhaust ports. In this manner, maximum power is derived from the cylinder with the least expenditure of scavengingpump power. In practice, such an objective is never attainable, hence the excellence of the scavenging process must be judged by the mass of fresh charge retained in the engine cylinder per unit time, in relation to the mass of fresh charge supplied per unit time by the scavenging pump.

It follows from the above that two mass rates per unit time, viz., that supplied by the scavenging pump and that retained in the engine cylinder, are required to define the scavenging characteristics of an engine. Of these two quantities, the mass supplied by the scavenging pump per unit time can be directly measured by the use of a flowmeter placed in the inlet system. The mass retained in the engine cylinder per unit time is not, however, subject to a direct measurement. For its determination, a number of indirect methods bave been devised and studied $[1,2] .{ }^{1}$ In general, such methods are either extremely laborious, or liable to considerable errors. This paper describes a rather simple method for the determination of an important related quantity, the mass fraction of fresh charge in the engine cylinder after port closure. On the basis of tests performed on a crankcase-scavenged engine, this method appeared to be quite practical and reliable.

\footnotetext{
${ }^{1}$ Figures in brackets indicate the literature references at the end of this paper.
}

\section{Nomenclature}

For analytical purposes, it is convenient to reduce the two mass rates mentioned above to nondimensional quantities. In this connection, several different systems of nondimensionalization $[1,3]$ have been proposed. Each proposed system has certain attractive features, thus the particular choice is, at least to some extent, a matter of personal preference.

A system rather similar to that employed by Taylor and Rogowski [1] is used. To nondimensionalize the mass of fresh charge supplied by the scavenging pump per unit time, the term "scavenging ratio", $R_{s}$, as defined below, is introduced,

$$
R_{s}=\frac{M_{g}}{\rho_{s} V_{d} N}
$$

To nondimensionalize the mass of fresh charge retained in the engine cylinder per unit time, the term "scavenging efficiency", $e_{s}$, is introduced,

$$
e_{s}=\frac{M_{r}}{\rho_{s} V_{d} N}
$$

where

$M_{g}=$ mass of fresh charge supplied by the scavenging pump per unit time,

$M_{r}=$ mass of fresh charge retained in the engine cylinder after port closure, per unit of time,

$\rho_{s}=$ density of fresh charge computed on the basis of inlet temperature and exhaust pressure,

$V_{d}=$ displacement volume,

$N=$ engine speed, revolutions per unit time.

In the above expressions, displacement volume $V_{d}$ is used basically as a matter of convenience, for this is the volume used in defining the mean effective pressure of the engine. The introduction of exhaust pressure into density term $\rho_{s}$ is especially convenient for engines with late exhaust closing, in which the exhaust pressure rather than the inlet pressure exercises controlling influence on the density of the cylinder contents at the time of port closure. 
For the purpose of the present paper, it is helpful to note that the quantity $M_{r}$ is related to the cylinder volume at the instant of port closure, as follows:

$$
M_{r}=\epsilon \rho_{x} V_{x} N
$$

where

$\epsilon=$ mass fraction of fresh charge in the engine cylinder after port closure,

$\rho_{x}=$ average density of the cylinder contents at the instant of port closure,

$V_{x}=$ cylinder volume at the instant of port closure.

Combining eq (2) and (3), the scavenging efficiency may then be written

$$
e_{s}=\epsilon\left(\rho_{x} / \rho_{s}\right)\left(V_{x} / V_{d}\right) .
$$

This paper deals with a method for the determination of the quantity $\epsilon$, and eq (4) shows the relation between this quantity and scavenging efficiency. The ratio $V_{x} / V_{d}$ is obviously determined by port timing. No attempt has been made to determine the ratio $\rho_{x} / \rho_{s}$ in the present investigation. However, some qualitative remarks may be in order here. The ratio $\rho_{x} / \rho_{s}$ is, in general, influenced by heat transfer between the fresh charge and the engine parts, flow resistance at the inlet and exhaust ports, and the dynamics of flow in the scavenging system. For engines with late exhaust closing, if the heat transfer, flow resistance, and flow dynamics effects were negligible, then the ratio $\rho_{x} / \rho_{s}$ obviously would become unity. Thus, $\rho_{x} / \rho_{s}$ provides a measure of the combined effect of heat transfer, flow resistance and flow dynamics in this instance.

For engines with late inlet closing, the relation may best be examined by writing

$$
\rho_{x} / \rho_{s}=\left(\rho_{x} / \rho_{i}\right)\left(\rho_{i} / \rho_{s}\right)=\left(\rho_{x} / \rho_{i}\right)\left(p_{i} / p_{e}\right),
$$

where

$\rho_{i}=$ density of fresh charge at inlet temperature and inlet pressure,

$p_{t}=$ inlet pressure, absolute,

$p_{e}=$ exhaust pressure, absolute.

Applying this expression to eq (4),

$$
e_{s}=\epsilon\left(\rho_{x} / \rho_{i}\right)\left(p_{i} / p_{e}\right)\left(V_{x} / V_{d}\right) .
$$

Here the ratio $p_{i} / p_{e}$ accounts for the static effect of inlet pressure, as against the exhaust pressure used in the definition of scavenging efficiency. For engines with late inlet closing, the ratio $\rho_{x} / \rho_{i}$ provides a measure of the combined effect of heat transfer, flow resistance, and flow dynamics. In the ideal case where these effects are negligible, the ratio $\rho_{x} / \rho_{i}$ reduces to unity.

\section{Principle of Skip-Cycle Method}

In the normal operation of a two-stroke cycle engine, when the engine fires every cycle, the cylinder is full of combustion products at the begin- ning of the scavenging process. At the end of the scavenging process, only a fraction of the combustion products remains in the cylinder. Now, consider the case when the engine is allowed to fire for one cycle and then skip, or run without firing, for several cycles. Obviously, any combustion products that remain in the cylinder must come from the firing cycle. Accordingly, the progressive scavenging action of the skipped cycles results in progressively less combustion products, or progressively more fresh charge, in the cylinder after each skipped cycle.

The above condition can be rather satisfactorily represented by a simple mathematical relationship. Let $f$ denote the mass fraction of residual gas retained in the cylinder during normal operation. The mass fraction of fresh charge during normal operation is then

$$
\epsilon=1-f \text {. }
$$

Let it be assumed that the conditions of heat transfer, flow resistance and flow dynamics are not significantly influenced by skip cycling - an assumption which appears to be justified by the experimental results reported herein. In that case, the total mass of retained cylinder contents would remain substantially constant, and likewise the mass fraction of cylinder contents to be passed from one cycle to the next. Consequently, if the engine is allowed to fire only once in $n$ cycles of operation, then for each of the firing cycles, the mass fraction of combustion products remaining in the cylinder would be $f^{n}$, and the mass fraction of fresh charge in the cylinder after port closure would be

$$
\boldsymbol{\epsilon}_{n}=1-f^{n} .
$$

Figure 1 gives a plot of $\left(1-f^{n}\right) /(1-f)$ versus $f$, for several values of $n$. The curve for $n=\infty$ represents the limiting case where the cylinder contains nothing but fresh charge.

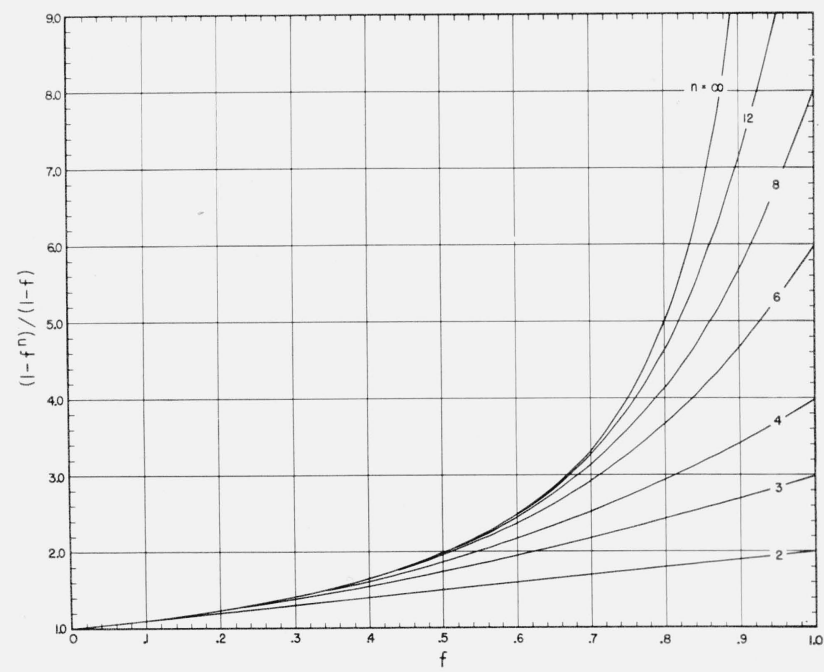

Figure 1. Plot of $\left(1-f^{n}\right) /(1-f)$ versus $f$. 
The skip-cycle method for the determination of $\epsilon$ is based on the premise that at constant fuel-air ratio and best-power ignition timing, the indicated thermal efficiency of a given internal combustion engine is very nearly constant over a wide range of operating conditions. The indicated mean effective pressure of a two-stroke cycle engine supplied with a premixed fuel-air charge, and operating normally, can be expressed, in terms of scavenging efficiency defined previously, as follows,

$$
\text { imep }=J e_{s} \rho_{s} F E_{c} \eta_{i},
$$

where

ime $p=$ indicated mean effective pressure (normal operation),

$F=$ fuel-air ratio,

$E_{c}=$ heating value of the fuel,

$\eta_{i}=$ indicated thermal efficiency based on fuel quantity retained in the cylinder, $J=$ mechanical equivalent of heat.

Applying eq (4) to this expression,

$$
\text { imep }=J \epsilon \rho_{x}\left(V_{x} / V_{d}\right) F E_{c} \eta_{i} .
$$

Under skip-cycle operation, eq (9) can be modified to read

$$
\operatorname{imep}_{n}=J \epsilon_{n} \rho_{x}\left(V_{x} / V_{d}\right) F E_{c} \eta_{i},
$$

where $i m e p_{n}$ is the imep of the firing cycle with firing occurring once every $n$ cycles of operation. The quantities $\rho_{x}, F$, and $\eta_{i}$ are constant, under the assumptions made previously.

Combining eq (9) and (10), and introducing the values for $\epsilon$ and $\epsilon_{n}$ as given by eq (6) and (7),

$$
\frac{i m e p_{n}}{i m e p}=\frac{\epsilon}{\epsilon_{n}}=\frac{1-f^{n}}{1-f} .
$$

It is seen that as $n$ approaches infinity, $\epsilon_{n}$ approaches unity for any value of $f$ less than unity, in which case $\epsilon=$ imep/imep $p_{\infty}$ as a limit. This relationship, though simple, is unfortunately difficult to apply in practical determination of $\epsilon$, because it is difficult to extrapolate with any reasonable accuracy for the value of $i m e p_{\infty}$ from readings taken with the necessarily limited values of $n$ in any practical experiment. Experience indicates that it is far more satisfactory to solve for the value of $f$ from the ratio of $i m e p_{n} /$ imep for finite values of $n$, and then obtain $\epsilon=1-f$. Figure 1 can conveniently be used for this operation.

\section{Experimental Equipment}

A small single-cylinder, air-cooled, crankcasescavenged engine was used for the experimental investigation. The principal dimensions of this engine are as follows:

Bore

Stroke.

Displacement volume

Cylinder compression ratio

Crankcase compression ratio
2. $500 \mathrm{in}$. 2. $000 \mathrm{in}$

9. $818 \mathrm{in}^{3}$

7. 05

1. 44
The engine employs conventional loop scavenging. The total transfer port area at the crankcase is 1.27 in. $^{2}$, the total inlet port area is 1.41 in. $^{2}$, and the total exhaust port area is $0.89 \mathrm{in.}^{2}$ The rotary valve has a maximum opening of 1.32 in. $^{2}$ The port timing of the engine is shown in figure 2 .

The engine was connected to a small electric dynamometer. The engine speed was measured by an electric tachometer, accurate speed control being accomplished with the aid of a stroboscope directed upon a striped flywheel. An MIT hydraulic scale [4] was used for dynamometer torque measurement.

Figure 3 is a schematic diagram of the experimental set-up. As indicated, air was supplied by a centrifugal blower, through appropriate controlling and measuring devices, to the engine rotary valve inlet (herein defined as the engine inlet). Fuel (a 20:1 gasoline-oil mixture) was supplied under pressure, through appropriate controlling and measuring devices, to the inlet surge tank, where it was mixed

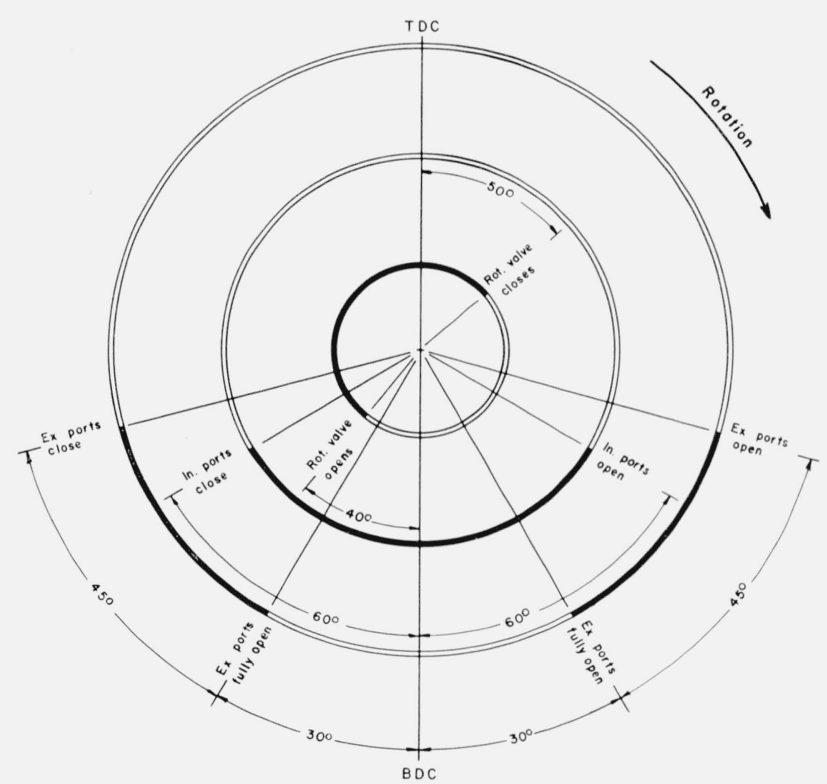

Figure 2. Port timing of the engine used in the experiment.

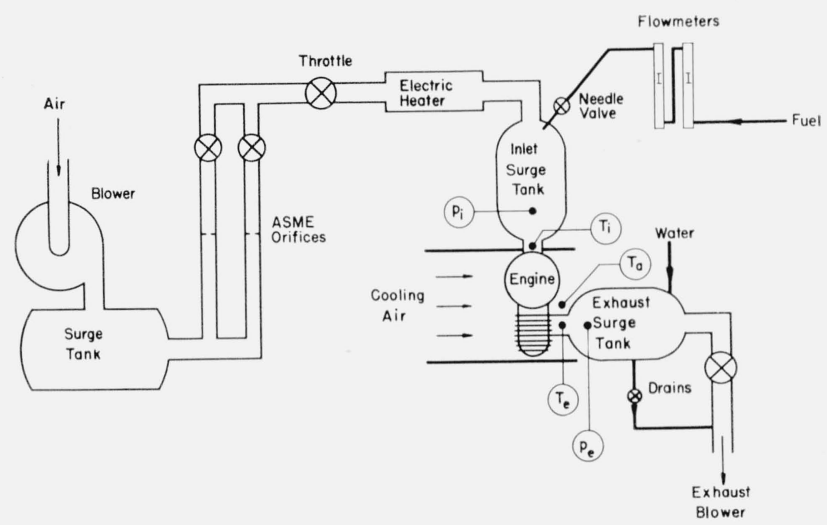

Figure 3. Schematic diagram of the engine setup. 
with the inlet air. The air rate was measured by calibrated sharp-edged orifices of the ASME flange taps design [5]. Two orifices were used to cover the range of the experiment. Calibrated float-type flowmeters were used for fuel rate measurement. Again, two instruments were used to cover the entire experimental range.

The engine was enclosed in a duct, and was cooled by air supplied by a blower. The stations for the measurement of pressures and temperatures are indicated in the figure. All temperatures were measured by means of thermocouples. The pressures were measured by mercury and water manometers.

Figure 4 shows the ignition circuit used in the experiment. The circuit was designed basically to operate as a conventional automotive ignition system. There were four sets of breakers: the main breaker, a, operating at crankshaft speed, and the auxiliary breakers, b, c, and d, operating at reduced speeds. The reduced speeds were obtair ed by mounting the camshafts, $b, c$, and $d$, in a gearbox giving speeds in the progression of $1,1 / 2$, and $1 / 4$. The whole assembly was then driven through chain and sprockets by the crankshaft. The sprockets could be changed to furnish a speed ratio of either 2 or 3 between the crankshaft and shaft $b$. In this fashion, the auxiliary breakers could operate at either 1/2, 1/4, and $1 / 8$ of crankshaft speed, or $1 / 3,1 / 6$, and $1 / 12$ of crankshaft speed.

The main breaker was used to control the spark advance at all times. The spark advance was read by an automotive timing light. To obtain normal operation $(n=1)$, switch A should be closed, in which case a spark would be produced every time the main breaker was opened. For skip-cycle operation, the switch giving the desired value of $n$ should be closed and all other switches opened. In that case, the primary circuit would be completed only for the cycle for which ignition was desired. For that cycle, a spark would be produced at the instant the main breaker was opened.

The indicated mean effective pressure, imep, was computed from dynamometer readings taken with engine firing and motoring, by the familiar relation

$$
\text { imep }=C\left(P_{b}+P_{f}\right),
$$

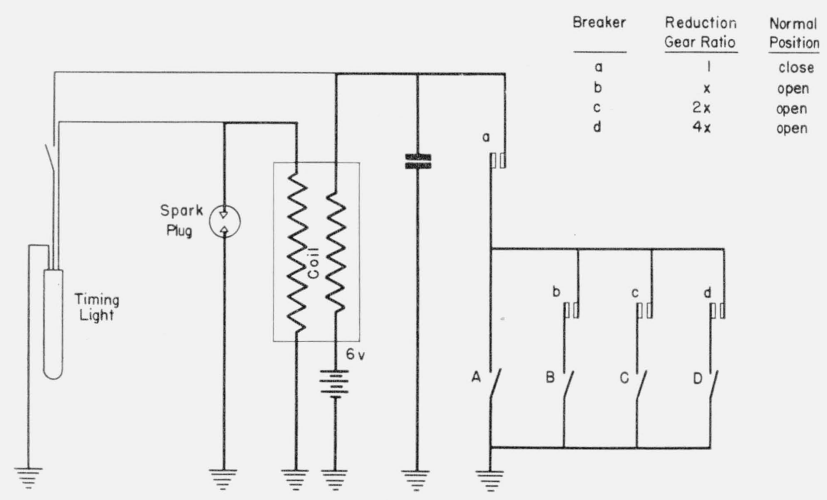

Figure 4. Circuit diagram of the ignition system. where

$C=\mathrm{a}$ constant,

$P_{b}=$ dynamometer reading taken with engine firing,

$P_{f}=$ dynamometer reading taken with engine motoring.

Under skip-cycle operation, the indicated mean effective pressure of the firing cycle, $i m e p_{n}$, was computed from the dynamometer readings as follows

$$
\text { imep }_{n}=n C\left(P_{b}+P_{f}\right),
$$

where $n$, as defined earlier, is the number of cycles of operation per firing cycle.

\section{Results and Discussion}

Three series of runs were made, with the engine speed, inlet pressure and exhaust pressure varied independently. With the exception of the variable whose effect was being measured, all operating variables were maintained constant at values shown below:

$$
\begin{aligned}
& N \text {, engine speed _...........rpm__ 1, } 800 \\
& p_{i} \text {, inlet pressure (inches of mercury, } \\
& \text { absolute) ... "Hga } \\
& p_{e} \text {, exhaust pressure.......... }{ }^{\prime \prime} \mathrm{Hga} \\
& T_{i} \text {, inlet temperature } \\
& T_{a} \text {, cooling air outlet temperature } \\
& F \text {, fuel-air ratio } \\
& { }^{\circ} \mathrm{F} \\
& 92 \pm 0.0 \\
& \text { 29. } 92+0.03 \\
& 100 \pm 1 \\
& 130 \pm 3 \\
& \text { 0. } 080 \pm 0.001
\end{aligned}
$$

The highest engine speed used in this experiment was 3,000 rpm. Limitation of the dynamometer, as well as vibrations of the installation, did not permit operation at higher speeds.

Figure 5 shows the variation of $i m e p, i h p$, and airflow rate, $M_{g}$, of the engine, under best-power sparkadvance conditions, over a fairly wide range of engine speed, inlet pressure, and exhaust pressure.

Figure 6 shows the variation of imep $p_{n}$ versus spark advance under skip-cycle conditions, at 1,800 rpm. Note the progressive decrease in best-power spark advance, and the progressive increase in imep $p_{n}$, as the value of $n$ was increased. ${ }^{2}$ An indication of the degree of reproducibility of the experiment can be had by noting that results of three sets of runs, made on three different occasions, have been included in this figure.

From data presented in the form of figure 6 , the values of best-power spark advance and imep $p_{n}$ under best-power spark-advance conditions, could be derived for each set of operating conditions. In this manner, figures 7 and 8 were constructed. Note how the $i m e p_{n}$ curves with varied exhaust pressure cross each other, and cross the curves with varied inlet pressure (fig. 8). This behavior clearly shows that a variation of exhaust pressure affected not only $\epsilon$, but also $\rho_{x}$, in eq (9).

The imep $p_{n}$ imep curves shown in figures 9 and 10 were derived from the $i m e p_{n}$ data presented in figures

2 The variation of the best-power spark advance reflects the effect of $\epsilon$ on flame speed. The variation of $i m e p_{n}$ is expected on the basis of eq (11). 

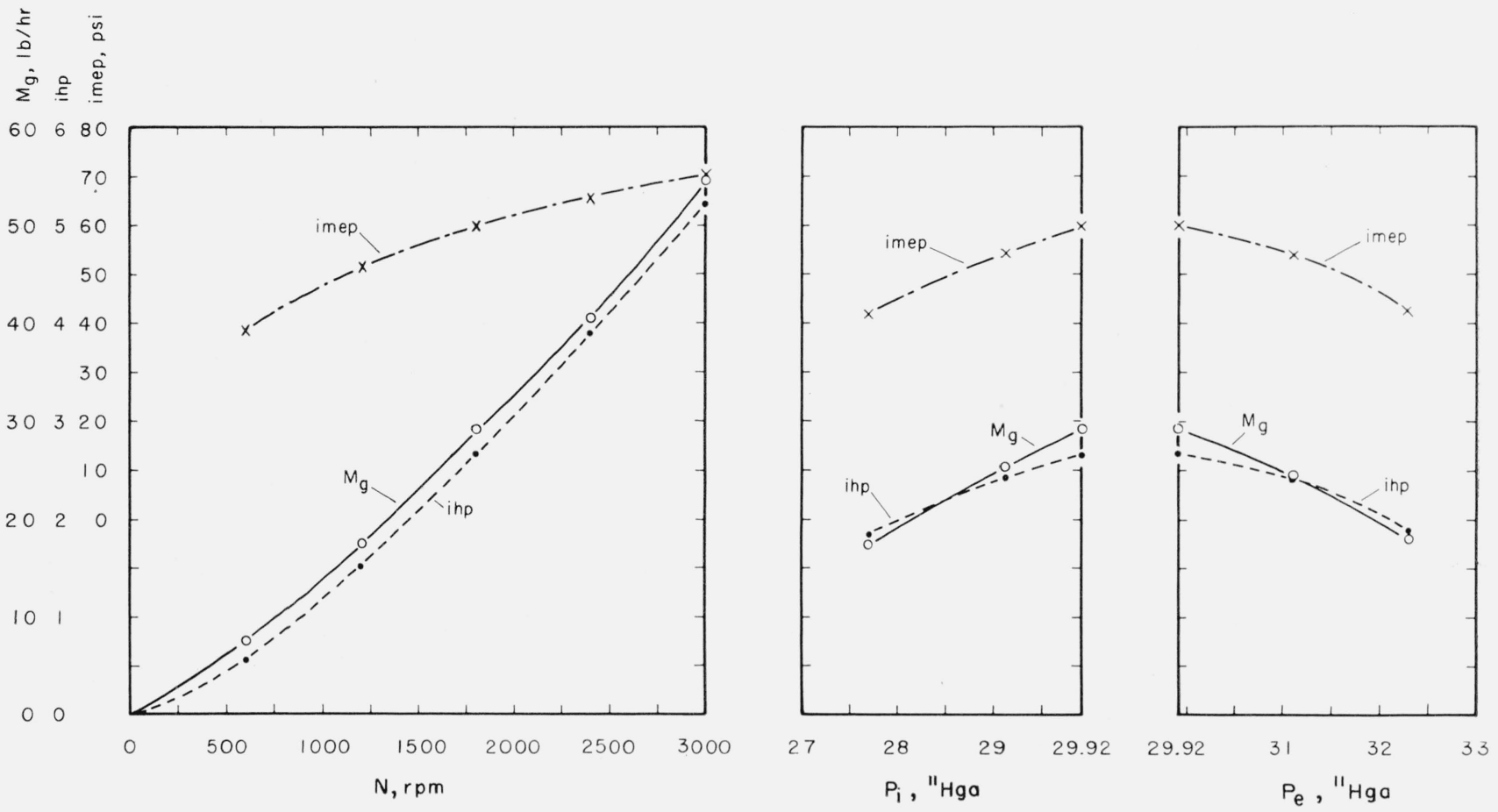

Figure 5. Performance characteristics of the engine.

Operating conditions (unless otherwise specified): 1,800 rpm, ${ }^{\prime} p_{i}=p_{e}=29.92^{\prime \prime}$. Hga, $" T T_{i}=100^{\circ} \mathrm{F}$, fuel-air ratio $=0.080$. best-power spark advance.
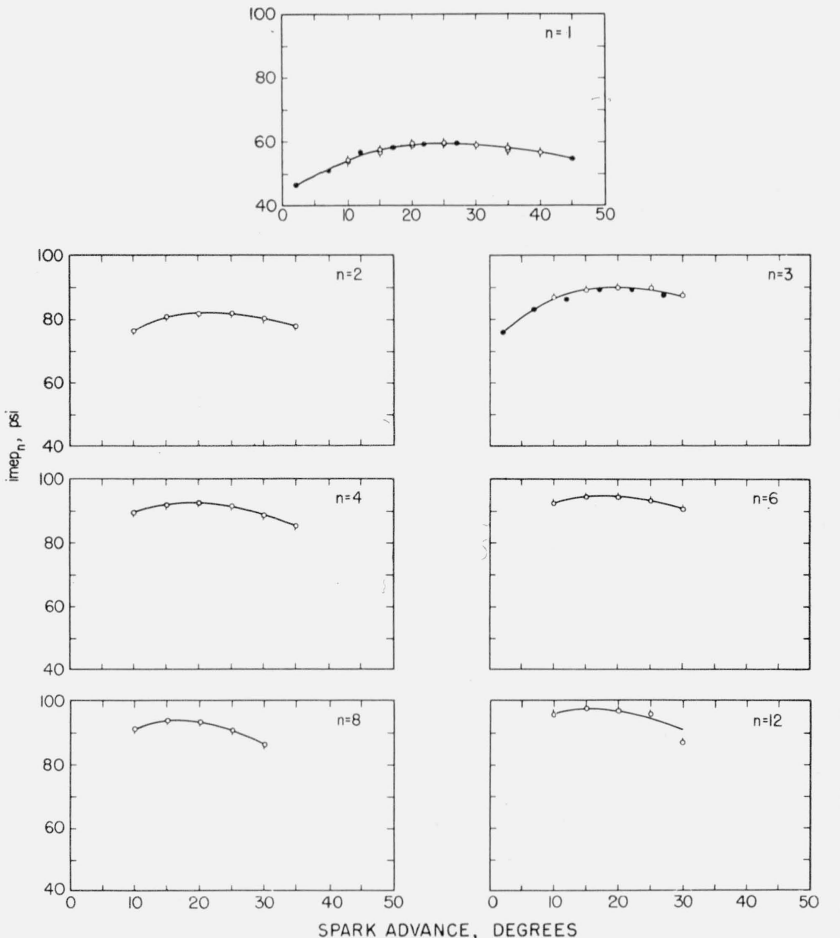

Figure 6. Imep $p_{n}$ versus spark advance, for varying degrees of skip cycling.

Operating conditions: $1,800 \mathrm{rpm}, p_{i}=p_{e}=29.92^{\prime \prime} \mathrm{Hga}, T_{i}=100^{\circ} \mathrm{F}$, fuel-air ratio $=$ 0.080. The three different symbols denote results of three runs under identical conditions, made on three different occasions.
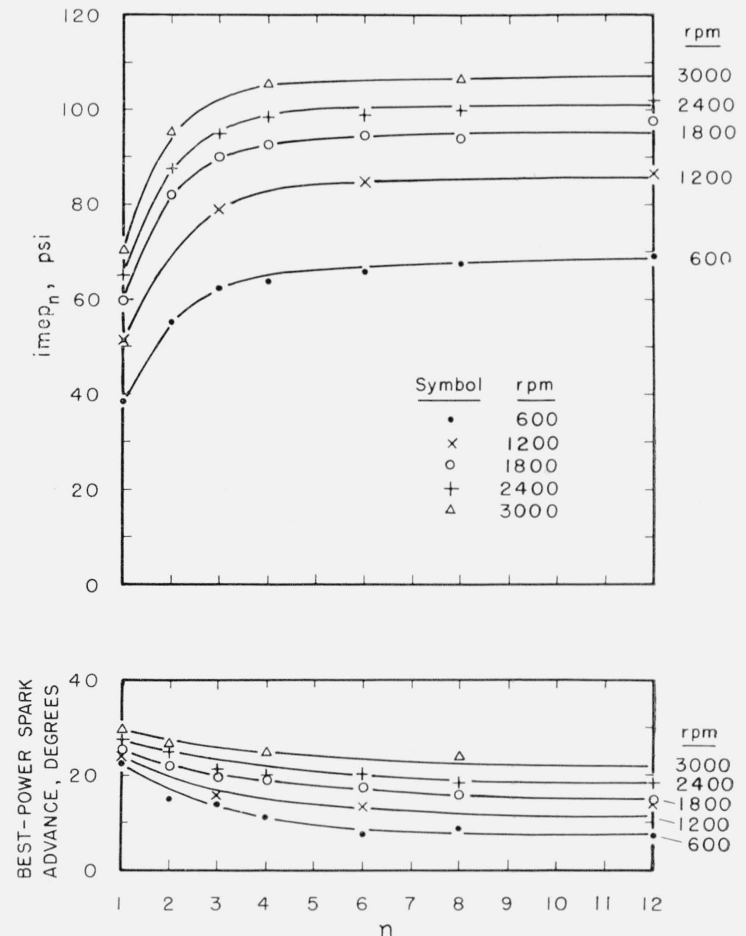

Figure 7. Best-power spark advance and imep ${ }_{n}$ at best-power spark advance as affected by skip cycling, at several engine speeds.

Operating conditions: $p_{i}=p_{e}=29.92^{\prime \prime} \mathrm{Hga}, T_{i}=100^{\circ} \mathrm{F}$, fuel-air ratio $=0.080$. 

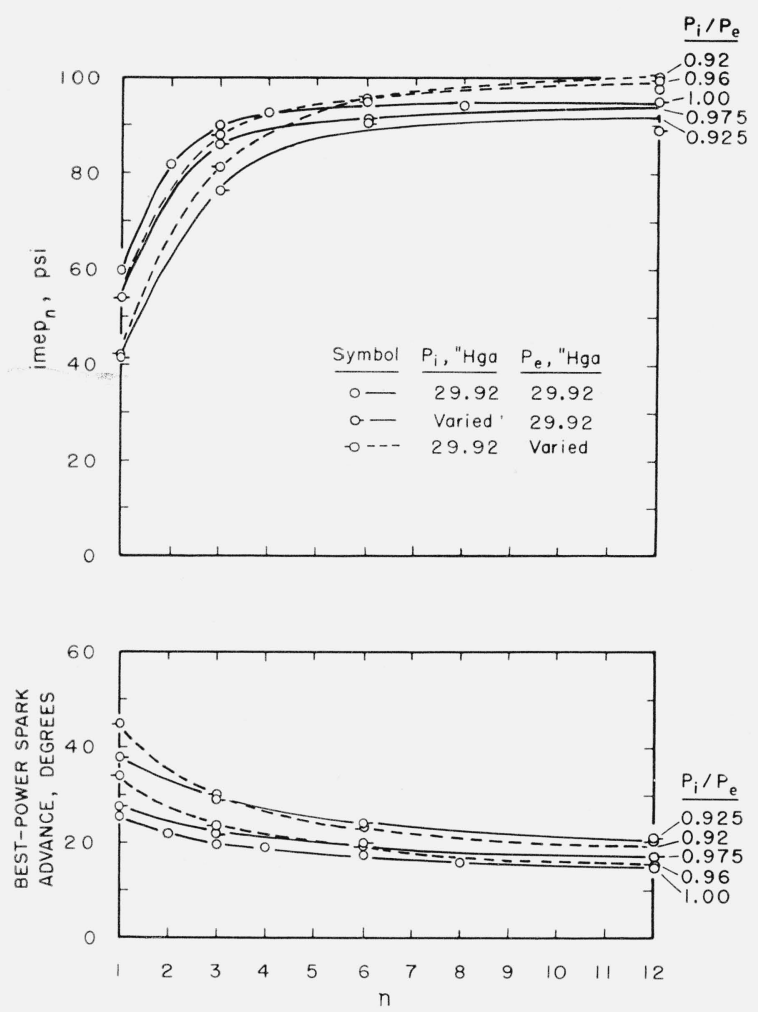

Figure 8. Best-power spark advance and imep it $_{n}$ at best-power spark advance as affected by skip cycling, at several inlet and exhaust pressures.

Operating conditions: $1,800 \mathrm{rpm}, T_{i}=100^{\circ} \mathrm{F}$, fuel-air ratio $=0.080$.
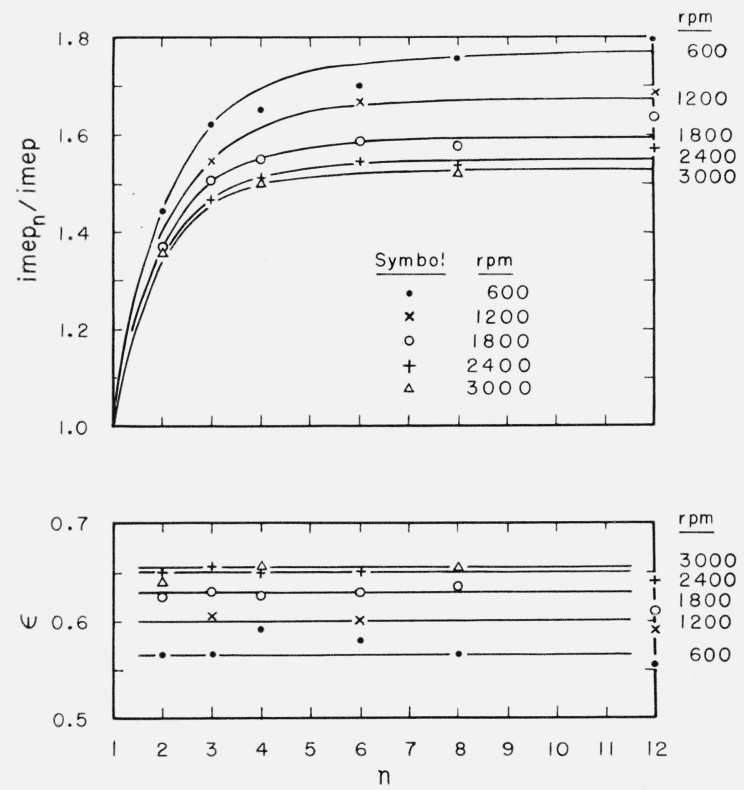

FIGURE 9. Mass fraction of fresh charge in the cylinder, at several engine speeds.

Operating conditions: see figure 7.
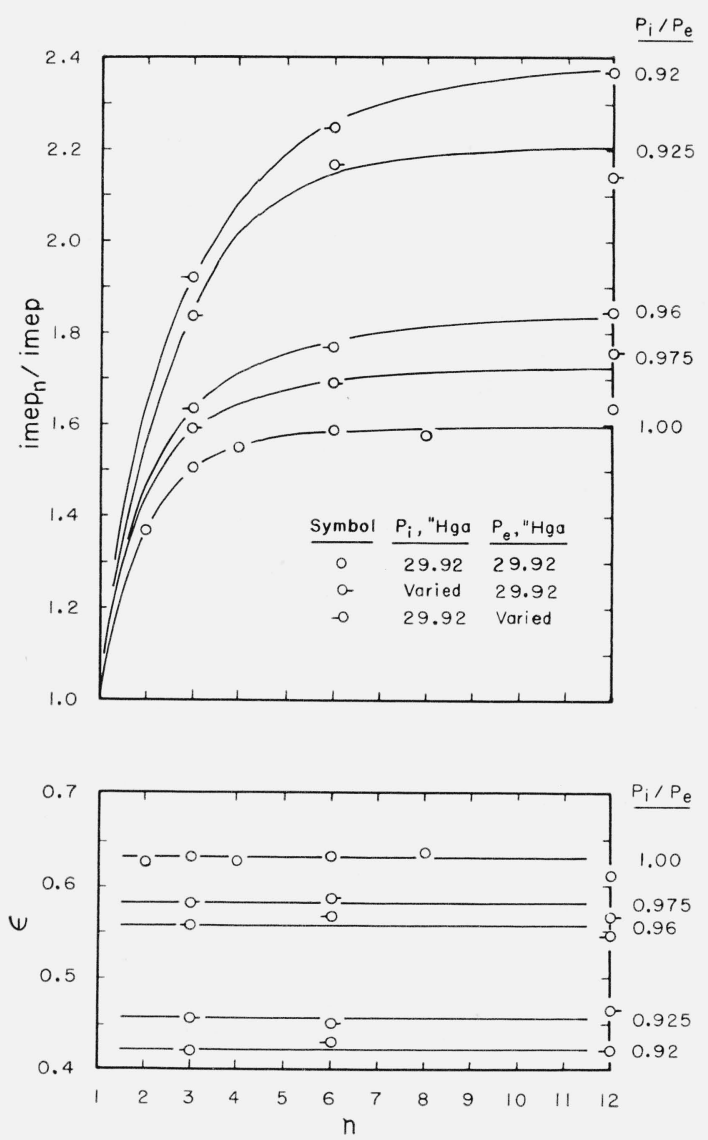

Figure 10. Mass fraction of fresh charge in the cylinder, at several values of $p_{i} / p_{e}$.

Operating conditions: see figure 8 .

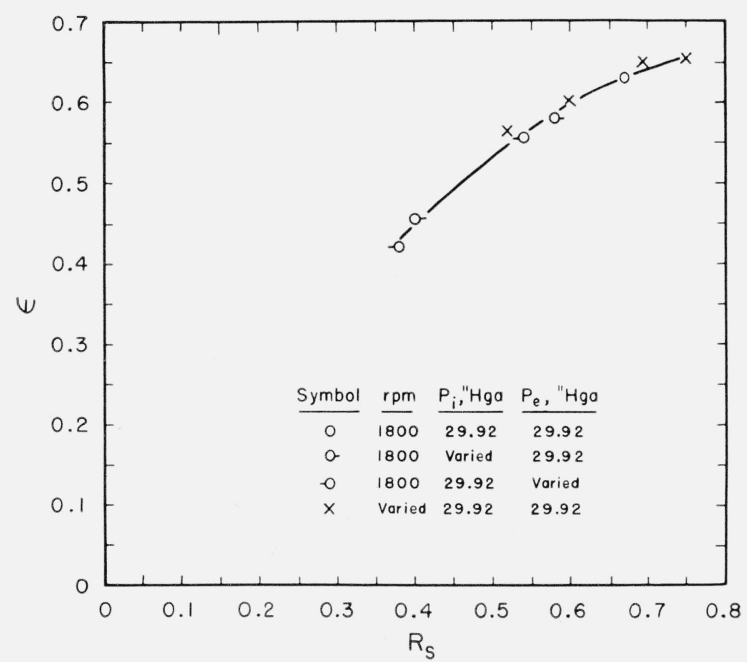

FIgure 11. Mass fraction of fresh charge in the cylinder as a function of scavenging ratio, for range of engine speed, inlet pressure and exhaust pressure investigated.

Operating conditions: $T_{i}=100^{\circ} \mathrm{F}$, fuel-air ratio $=0.08$. 
7 and 8 . Note that because the variable $\rho_{x}$ was eliminated in this method of presentation, the $i m e p_{n} /$ imep curves in figure 10 appeared in a systematic order with respect to the ratio $p_{i} / p_{e}$.

Figures 9 and 10 also present the values of $\epsilon$, as derived from the $i m e p_{n} /$ imep data given in the same figures, by the method outlined in section 3 . Note that the value of $\epsilon$ for each case remained substantially constant over the range of $n$ investigated. This constancy of the value of $\epsilon$ is gratifying, in view of the complexity of the scavenging process and the simplifying assumptions made. By averaging the results obtained at several values of $n$, a rather reliable value for $\epsilon$ may thus be derived.

The results presented in figures 9 and 10 are summarized in figure 11. It is interesting to note that the mass fraction of fresh charge in the cylinder was, within experimental accuracy, a function of scavenging ratio only, regardless of the individual values of engine speed, inlet pressure, or exhaust pressure, within the range of the variables investigated.
The assistance provided by Edward Bryant in setting up the experimental equipment and in operating the engine is gratefully acknowledged.

\section{References}

[1] C. F. Taylor and A. R. Rogowski, Scavenging the twostroke engine, SAE Trans. 62, 486 (1954).

[2] P. H. Schweitzer, Scavenging of two-stroke cycle diesel engines, ch. 16 (The Macmillan Co., New York, N. Y., 1949).

[3] P. H. Schweitzer, Scavenging of two-stroke cycle diesel engines, ch. 3 (The Macmillan Co., New York, N. Y., 1949).

[4] Hydraulic scale for measurement of engine dynamometer forces, Laboratory Equipment Bulletin No. 6, Diesel Engine Manufacturers Association (January 3, 1949).

[5] Fluid meters - their theory and application, Report of ASME Special Research Committee on Fluid Meters, pt I (1937).

Washington, April 5, 1956. 